\title{
Current Management of Pectus Excavatum: A Review and Update of Therapy and Treatment Recommendations
}

\author{
Dawn Jaroszewski, MD, David Notrica, MD, Lisa McMahon, MD, \\ D. Eric Steidley, MD, and Claude Deschamps, $M D$
}

Pectus excavatum (PE) is a posterior depression of the sternum and adjacent costal cartilages and is frequently seen by primary care providers. PE accounts for $>90 \%$ of congenital chest wall deformities. Patients with PE are often dismissed by physicians as having an inconsequential problem; however, it can be more than a cosmetic deformity. Severe cases can cause cardiopulmonary impairment and physiologic limitations. Evidence continues to present that these physiologic impairments may worsen as the patient ages. Data reports improved cardiopulmonary function after repair and marked improvement in psychosocial function. More recent consensus by both the pediatric and thoracic surgical communities validates surgical repair of the significant $P E$ and contradicts arguments that repair is primarily cosmetic. We performed a review of the current literature and treatment recommendations for patients with PE deformities. (J Am Board Fam Med 2010;23:230-239.)

Keywords: Pectus Excavatum, Chest Wall Deformities, Congenital Defects, Cardiovascular Disorders, Musculoskeletal and Connective Tissue, Review

Pectus chest deformities are among the most common major congenital anomalies found in patients in the United States. They occur in approximately 1 of every 300 to 400 white male births. ${ }^{1-3}$ Men are afflicted 5 times more often than women. ${ }^{2,4}$ The condition is uncommon among African Americans and Latinos. ${ }^{2,5}$ Pectus excavatum (PE) with sternal depression is approximately 6 times more common than pectus carinatum (protrusion). ${ }^{4,5}$ The cause of PE remains unknown. Approximately $40 \%$ of patients with pectus deformities have family members who also have deformities, although a direct ge-

This article was externally peer reviewed.

Submitted 9 June 2008; revised 5 October 2009; accepted 14 October 2009.

From the Division of Cardiothoracic Surgery (DJ) and the Division of Cardiology (DES), Mayo Clinic Arizona, Scottsdale; the Pediatric Surgeons of Phoenix, Department of Pediatric Surgery, Phoenix Children's Hospital (DN, LM); and the Division of Thoracic Surgery, Mayo Clinic Rochester, Minnesota (CD).

Funding: none.

Conflict of interest: none declared.

Corresponding author: Dawn E. Jaroszewski, MD, Division of Cardiothoracic Surgery, Mayo Clinic Arizona, 5777 East Mayo Boulevard, Phoenix, AZ 85054 (E-mail: Jaroszewski.dawn@mayo.edu). netic link has not been identified. ${ }^{4,6-8}$ Disturbances in the growth of the sternum and costal arches, as well as biomechanical factors, are suspected in the pathogenesis. ${ }^{1,2,4,6,9-11}$ The involved cartilages can be fused, deformed, or rotated. Intrinsic abnormality of the costochondral cartilage is suggested by the significant occurrence of PE among patients with connective tissue disorders, such as Marfan syndrome. ${ }^{4,6,8,12}$ There is also a high percentage of scoliosis associated with the disorder. ${ }^{6-8,12}$ Abnormalities of the cartilages removed during surgery have also been reported, including stress/strain deformation and abnormal collagen content. ${ }^{1}$

$\mathrm{PE}$ can be present at birth but is most frequently recognized during early childhood. During rapid adolescent growth, many patients experience a marked increase in the severity of the depression until full skeletal maturity is achieved. ${ }^{5,13-20}$ In severe cases or those in which depressions directly impinge on the right ventricle, $\mathrm{PE}$ is more than a cosmetic deformity. ${ }^{21-24}$ Many patients do not undergo repair during childhood and subsequently experience progressive a worsening of symptoms and cardiopulmonary function with increasing age. ${ }^{18-20,24-26}$ 
Figure 1. Patient with a more focal classic "cupshaped" or "bowl-shaped" pectus excavatum deformity.

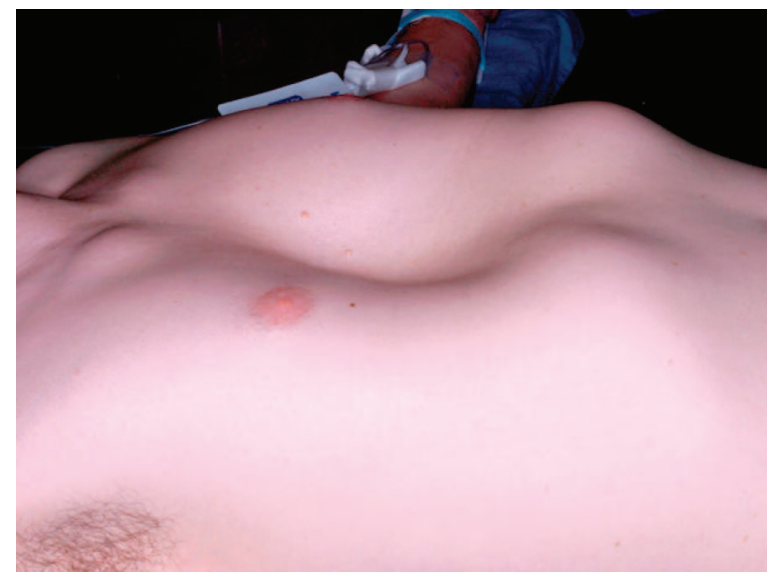

One theory for the worsening of symptoms that is experienced with age is that the chest wall is very compliant in infancy but, with aging, a steady decline in compliance is experienced and it becomes relatively stiffer compared with the lungs. In adults the loss of elasticity and flexibility of the chest can lead to cardiac symptoms with only moderate exertion. ${ }^{8,26}$ A similar phenomena is also seen in patients with scoliosis as they age. ${ }^{6,7}$ Publications regarding the surgical management of adult patients with pectus deformities are few, but have increased significantly during the past few years with greater recognition of the physiologic and psychologic impact of the disease. ${ }^{8,18,19,24,26-36}$ Despite well-documented reports to the contrary, the longstanding misconception persists that $\mathrm{PE}$ is a cosmetic defect with no physiologic consequences. This misconception has resulted in patients reaching adulthood with uncorrected defects. Some patients will develop cardiopulmonary symptoms for the first time as they age and others will experience a worsening of symptoms they have endured for years.

\section{Clinical Features}

The PE depression most frequently involves the lower sternum and cartilages but can be extensive with varying degrees of rotation and asymmetry. ${ }^{1,2,8,12}$ Deformities are seen in many different configurations, the most common being a cupshaped concavity. These are generally well defined, deep, and involve the lower end of the sternum with the depression of costal cartilages 4 through 7 (Figure 1). Patients can also have a significant ex-
Figure 2. A: Patient exhibiting a broad, more extensive pectus excavatum deformity. B: Patient with Marfan's syndrome and extensive pectus excavatum deformity.
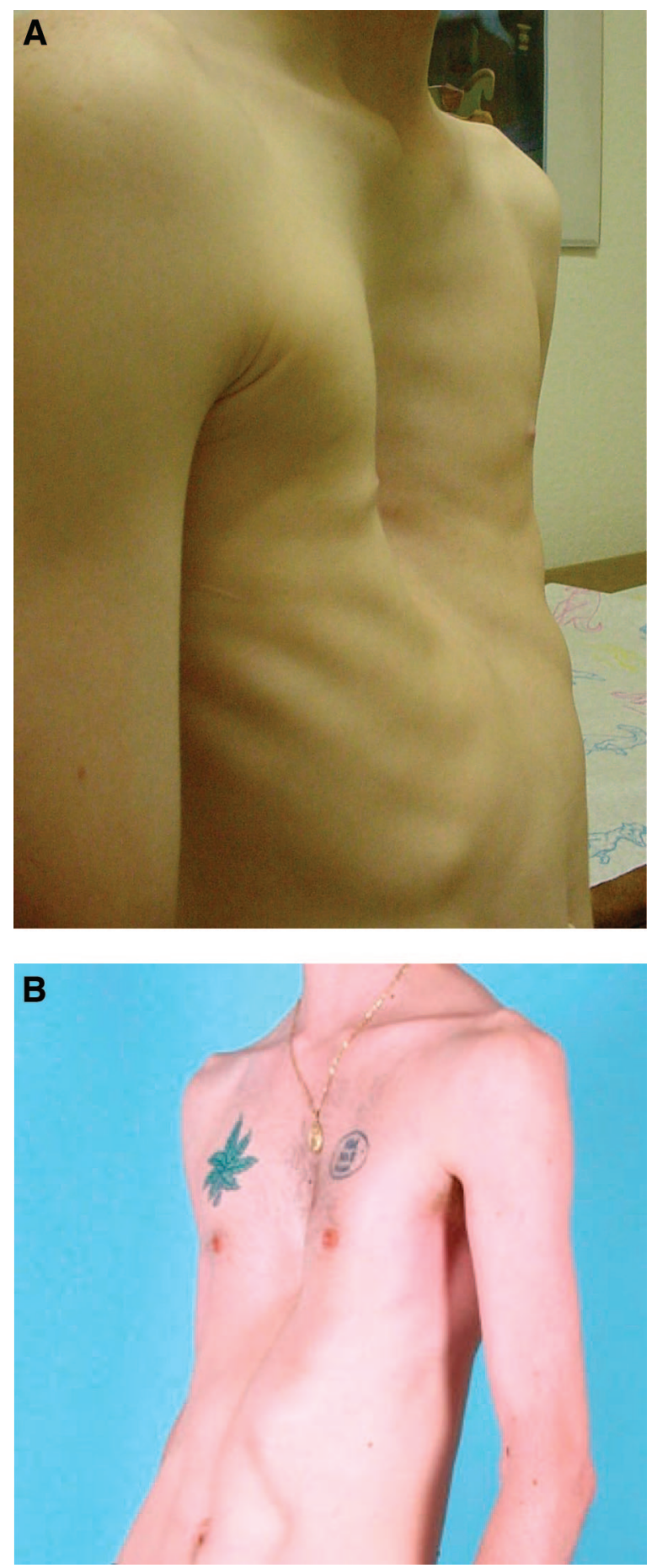

tensive depression with involvement of the upper costal cartilages, creating a more severe, broad form of concavity (Figure $2 \mathrm{~A}$ and B). ${ }^{2,8,36,37}$ 
Table 1. Most Frequent Symptoms of Pectus Excavatum Noted by Patients
1. Dyspnea with mild exercise
2. Progressive loss of endurance
3. Inability to keep up with peers
4. Chest pain with activity
5. Worsening, progressive fatigue
6. Palpitations
7. Tachycardia
8. Exercise induced wheezing
9. Frequent upper respiratory infections
10. Easy fatigue
11. Fainting/dizziness
12. Chest pain without exercise
13. Exercise intolerance

\section{Symptoms}

Patients with PE can present with many different symptoms. The symptoms often vary in severity and their effect on patient's daily activities. The severity of the defect does not necessarily correlate with the severity of symptoms. Many patients are asymptomatic at a younger age but start experiencing symptoms as they enter their teens. ${ }^{14,18,19,24,36}$ This may be because of a worsening of the defect or an increase in exercise and physical activity. The most consistently expressed symptoms are dyspnea with exercise and loss of endurance. A list of the common symptoms of $\mathrm{PE}$ is provided in Table $1 .^{3,8,13,14,17,18,30,36,38}$

Despite multiple studies evaluating cardiac and pulmonary function, there has been no conclusive or consistent demonstration of physiologic impact correlating with the symptoms of PE. Anatomic abnormalities, including decreased thoracic volume and cardiac compression, are thought to explain the physiologic effects noted by patients. ${ }^{17,36,37}$ The increased work of breathing from a partially restricted chest wall with impaired oxygen delivery to working muscles as the result of decreased venous return to the right heart may also play a role. ${ }^{16,17,23}$ Sternal compression is suspected to decrease thoracic volume, which can reduce the $\mathrm{SVO}_{2}$, exercise tolerance, tidal volume, and vital capacity, causing dyspnea and a decrease in endurance with compensatory tachypnea during exercise. ${ }^{13,16,39-41}$ Cardiac compression can also reduce stroke volume and cardiac output in severe deformities, causing accelerated fatigue and compensatory tachycardia. ${ }^{16,17,22-24,40}$ A systolic cardiac murmur is sometimes heard and mitral valve prolapse is found in as many as $25 \%$ of patients. ${ }^{4,5,31}$ The percentage of pectus patients with mitral valve prolapse seems to increase with age. ${ }^{3,31}$ Resolution of the mitral valve prolapse with release of the chest wall entrapment is seen in more than half of patients after surgery. ${ }^{8,15,17,31}$ Dysrhythmias can also be seen, including first-degree heart block, right bundle branch block, and Wolff Parkinson-White syndrome. $^{8,17,42}$

The psychosocial issues surrounding body image among teenagers can be significant, life-altering, and occasionally life-threatening. ${ }^{8,36,37}$ Poor body image and impaired psychosocial function is an enormously important concern for surgical repair. ${ }^{36,37}$ Children and adolescents with potentially visible physical differences may be at risk for body image and interpersonal difficulties. ${ }^{27}$ Psychological research about patients with disfigurement confirm disturbance of the body schema and altercation of the individual's self-representation. ${ }^{34}$ Surgical repair of PE can significantly improve the difficulties with body image and limitations on physical activity that are experienced by patients. ${ }^{20,36,37,43}$ These results should prompt physicians to consider the physiologic and psychological implications of PE just as they would any other physical deformity known to have such consequences. In a multicenter investigation, geographically dispersed children and adults demonstrated a marked effect of the chest deformity on perceived ability to exercise, which was consistently improved with surgical correction. ${ }^{19,20,35,37,43}$ The importance of these concerns to the child and family should not be underestimated by physicians. ${ }^{36,44}$

Investigation as to the cause of exercise intolerance and perceived limitation of ability have yielded mixed results, and whether surgical repair corrects these deficits is controversial. ${ }^{12,19,22,25,37,41,43}$ Malek et $\mathrm{al}^{22}$ and Malek and Marelich $^{41}$ performed a comprehensive metaanalysis on publications reporting postoperative cardiopulmonary results among PE patients. The critical finding of the study was that surgical repair improved cardiovascular function by more than $1 / 2$ standard deviation. The patient's personal testimony has been the most convincing evidence for repair. The majority of patients with symptoms reported significant improvement after repair. These findings, along with current ongoing investigations, further the argument 
that surgical repair of PE is indicated for symptomatic patients regardless of physiologic testing and is more than primarily cosmetic.

\section{Evaluation}

The presentation of a patient with $\mathrm{PE}$ warrants a thorough workup to access the significance of the defect. This workup does not necessarily include every possible physiologic test, but can include those necessary to determine whether the patient should be referred to a surgeon for a discussion of repair options.

\section{Radiographic Evaluation}

Imaging for anatomic assessment and documentation of the chest dimensions is important and remains a mainstay of the anatomic evaluation of PE. A noncontrast computerized tomographic (CT) scan is useful to access the deformity of the bony and cartilaginous skeleton in a 3-dimensional view, which clearly reveals any cardiac compression (Figure 3a) or cardiac displacement (Figure 3B). Magnetic resonance imaging can be used instead of CT scan to reduce radiation exposure but bony detail is better seen by a CT scan. ${ }^{8,17,25}$ An index of severity can be calculated by measuring the inner width of the chest (at the lowest level of the pectus defect) and dividing it by the distance between the posterior surface of the sternum (at the lowest part of the defect) and the anterior surface of the spine. ${ }^{17,28,45}$ The severity index for healthy people is $2.52 .{ }^{8,45} \mathrm{In}$ general, an index of $\geq 3.1$ is considered severe. . $^{2,3,5,8,13,14,17-19,25,46,47}$

\section{Electrocardiogram}

Documentation of any dysrhythmias should be done with a 12-lead electrocardiogram.

\section{Transthoracic or Transesophageal Echocardiogram}

It may be useful to perform an echocardiogram because the depressed sternum may compress the right atrium and right ventricle, interfering with diastolic filling of these structures. ${ }^{36}$ Mitral valve prolapse is commonly seen among patients with $\mathrm{PE}$ and should also be documented if it is present. Evaluation of the aortic root and valve is also critical in patients with suspected or confirmed Marfan syndrome.
Figure 3. Computerized tomographic scans of the chest showing left-sided heart displacement (A) and right ventricular compression (B) by severe pectus excavatum deformity.
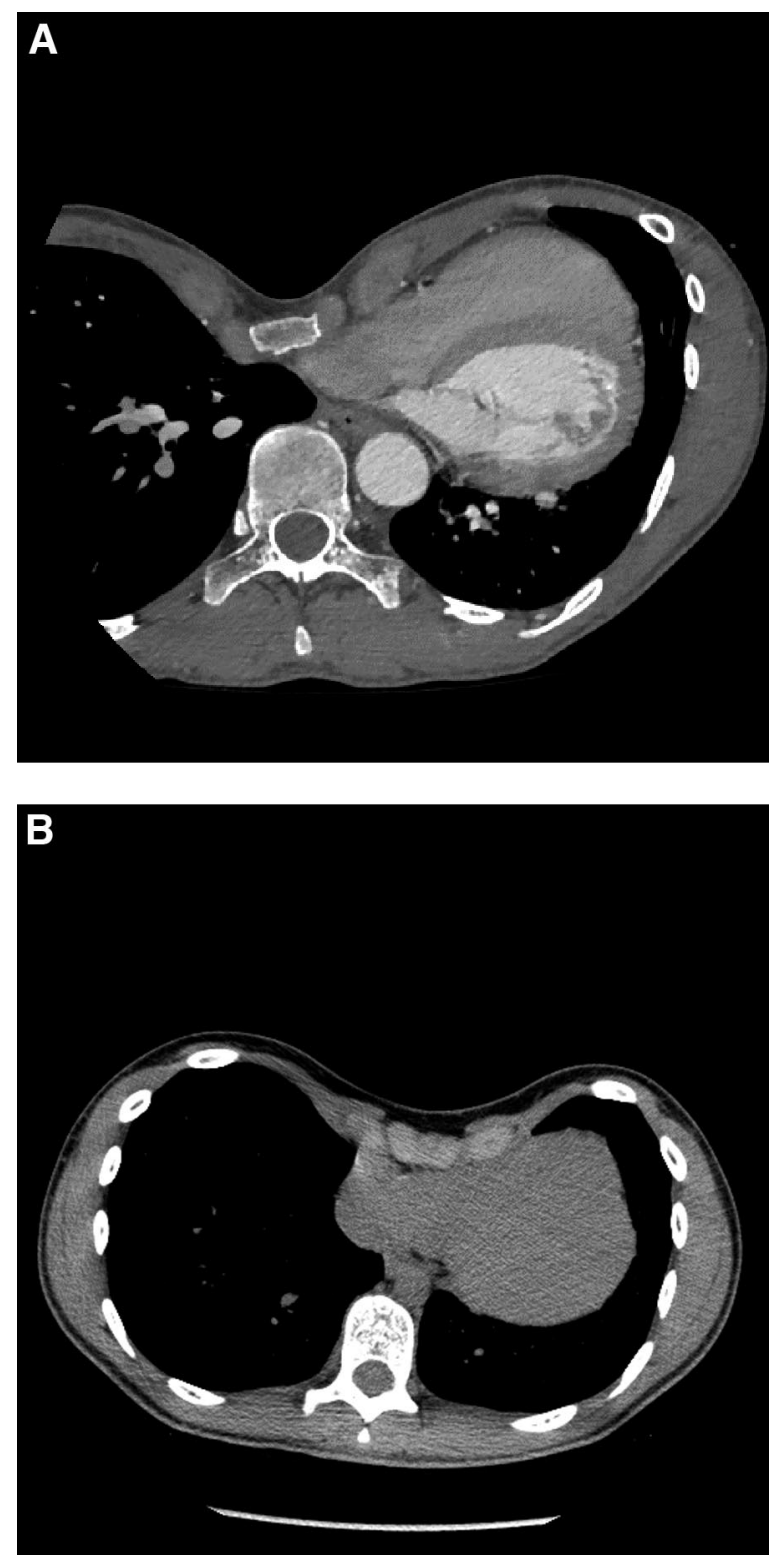

\section{Pulmonary Functions}

Both static and exercise pulmonary function tests may be useful in eliciting a physiologic effect of the PE defect on the patient. Static pulmonary function tests are the least sensitive but may show a significant decrease in forced vital capacity and maximal ventilatory volumes, which indicate restrictive airway disease. Patients may also have evidence of mild obstructive airway disease. In general, most patients with significant $\mathrm{PE}$ will 
Figure 4. Cardiopulmonary exercise testing $\mathrm{VO}_{2}$ /heart rate study from a symptomatic PE patient before (A) and after (B) operation.

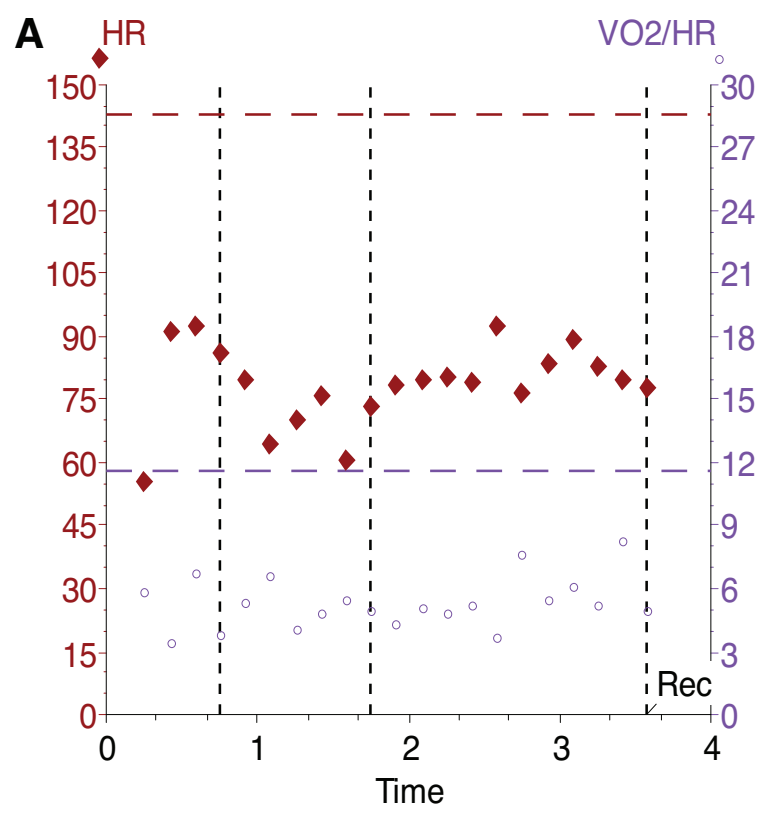

Pre-operative VO2/HR

still have a normal or low-normal static pulmonary function test.

\section{Cardiopulmonary Exercise Testing}

Cardiopulmonary exercise testing can also be used to show significant physiologic effects of the PE. The amount of oxygen that can be delivered to the tissues with exercise can be examined. A decrease in the $\mathrm{O}_{2}$ pulse (mL/beat) and amount of oxygen that could be delivered $\left(\mathrm{VO}_{2} \mathrm{~L} / \mathrm{min}\right.$ and $\left.\mathrm{V}_{\mathrm{e}} \mathrm{L} / \mathrm{min}\right)$ may be significantly below predicted values in patients with PE. ${ }^{24,36}$ Low-normal and below-normal values indicate that surgical correction could benefit the patient. ${ }^{22,24,25,36,48}$ Figures 4 and 5 show the cardiopulmonary exercise testing $\mathrm{Vo}_{2}$ /heart rate and $\mathrm{Vo}_{2} / \mathrm{CO}_{2}$ finding from a symptomatic $\mathrm{PE}$ patient before and after an operation.

\section{Indications for Surgery}

The primary care physician needs to have a good understanding of the disease and realize the importance of the deformity. Surgical correction of PE can be performed safely with minimal risk. Referral for consideration of surgical treatment for severe cases should be made. Operation for correction of $\mathrm{PE}$ is readily accomplished in teenagers, who are close to the age of skeletal maturity. ${ }^{5,29,36,38,47}$ The

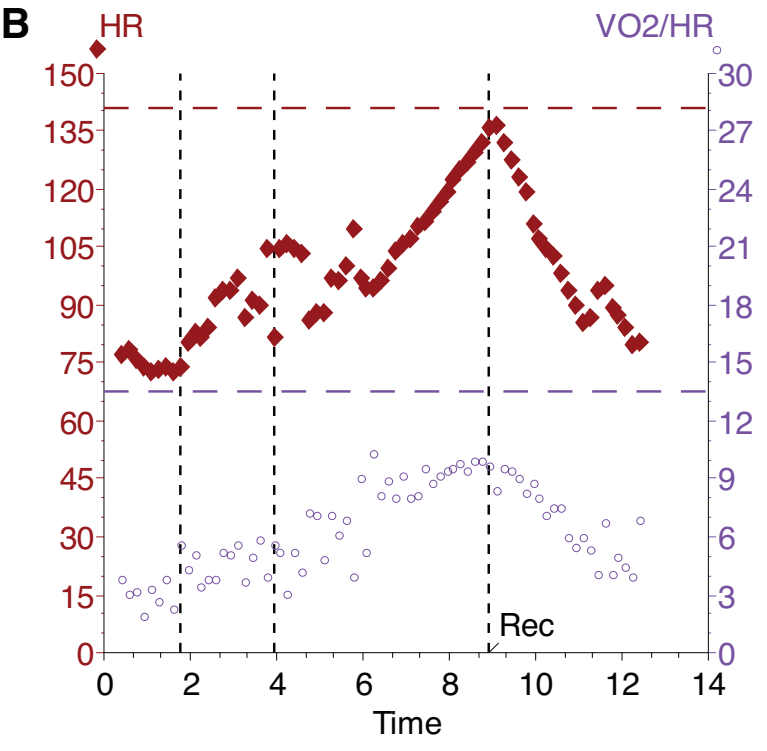

Post-operative VO2/HR

timing for surgery is problematic in the younger child. ${ }^{8,14,36,46,47,49}$ Currently, most surgeons will wait for patients to reach the adolescence or early teenage years to perform repair. Repair during the later stages of teenage growth allow the patient to complete their growth and have a lower chance of recurrence. Younger children with significant cardiopulmonary compromise may also be candidates for repair depending on the severity of their symptoms; however, repair at too early of an age can result in improper growth of the chest wall and other complications, including recurrences. ${ }^{3,29,30,36,49}$ Adult repair is also feasible and has been reported in patients as old as 78 years. ${ }^{18,19,24,26,29,30,32,50}$

In general, referral to a surgeon for consultation should occur when a patient demonstrates any of the criteria listed in Table 2. Most patients will be considered for surgical correction if they demonstrate at least 2 of the listed criteria. ${ }^{36}$ Others may need to be followed closely to watch for progression or worsening of the defect and symptoms as they age.

\section{Surgical Repair}

Surgical repair of PE has evolved significantly during the past 50 years. There are a variety of tech- 
Figure 5. Cardiopulmonary exercise testing $\mathrm{VO}_{2} / \mathrm{CO}_{2}$ study from a symptomatic PE patient, before (A) and after (B) operation.

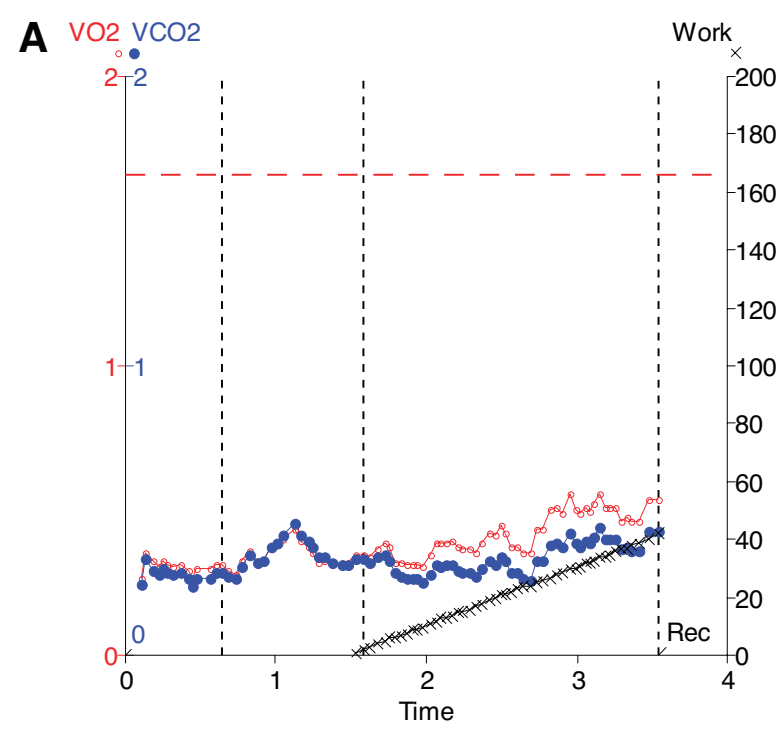

Pre-operative VO2/CO2 slope

niques that have been successfully used, but the 2 most common methods include modifications of the open approach, first described by Ravitch, ${ }^{14,21}$ and the Nuss, or minimally invasive, approach.

Modifications of the open repair as described by Ravitch have been used for decades and are still used routinely. ${ }^{5,14,15,19,28,46,51,52}$ The technique resects minimal cartilage and yields excellent results with low morbidity (Figure 6). ${ }^{14,15,46,51}$ There have been a variety of modifications reported, including the use of mesh, but the majority of procedures

\section{Table 2. Criteria for Surgical Referral}

\footnotetext{
1. Symptomatic

2. Progression of the deformity

3. Paradoxical movement of the chest wall with deep inspiration

4. Computed tomograph with severity index $>3.0$

5. Cardiac compression or displacement

6. Pulmonary compression

7. Abnormal pulmonary function studies showing significant restrictive disease

8. Mitral valve prolapse

9. Any cardiac pathology secondary to compression of the heart

10. Significant body image disturbance

History of failed previous repair

Abnormal cardiopulmonary testing
}

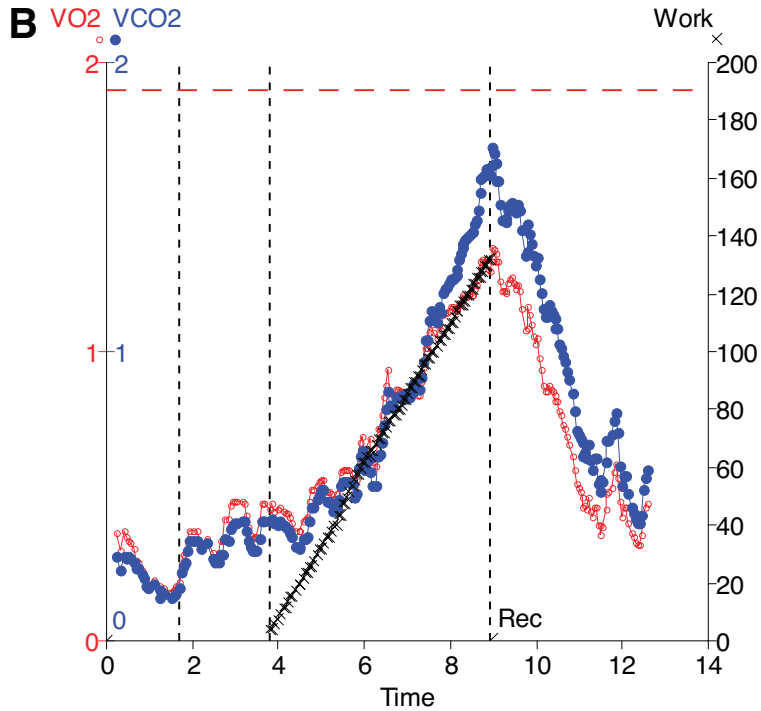

Post-operative VO2/CO2 slope

include placement of a metal strut to support the sternum, which may be left in place for 6 months to a year. Proponents of the modified Ravitch claim lower cost, shorter hospitalization, and less postoperative pain. ${ }^{38,46,53,54}$ It is ideal for patients who have a combination of $\mathrm{PE}$ and carinatum, significant asymmetry, or extensive defects involving the upper ribs and cartilage.

A minimally invasive technique for repair was described by Nuss et $\mathrm{al}^{42}$ in 1998 . This method of repair involves the placement of a substernal concave bar, which is passed behind the sternum through the chest and "flipped" into a convex position to elevate the sternum outward (Figure 7). The bar is left in place for 2 to 3 years while the anterior chest wall remodels. Cosmetic results are reported as good to excellent in $>85 \%$ of patients, and the operation has rapidly gained popularity because of the small skin incisions and shorter operative time. ${ }^{20,25,26,47,50}$ In recent years the operation has been successfully used to repair PE in adults, although higher rates of complications and postoperative pain have been reported. ${ }^{26,29,32,53}$ The advantages of the Nuss approach include avoiding an anterior chest wall incision, resection of rib cartilages, and no sternal osteotomy. Incorporation of thoracoscopic techniques has made the 
Figure 6. Schematic diagrams (A) and operative photographs (B and C) depicting the modified Ravitch procedure.
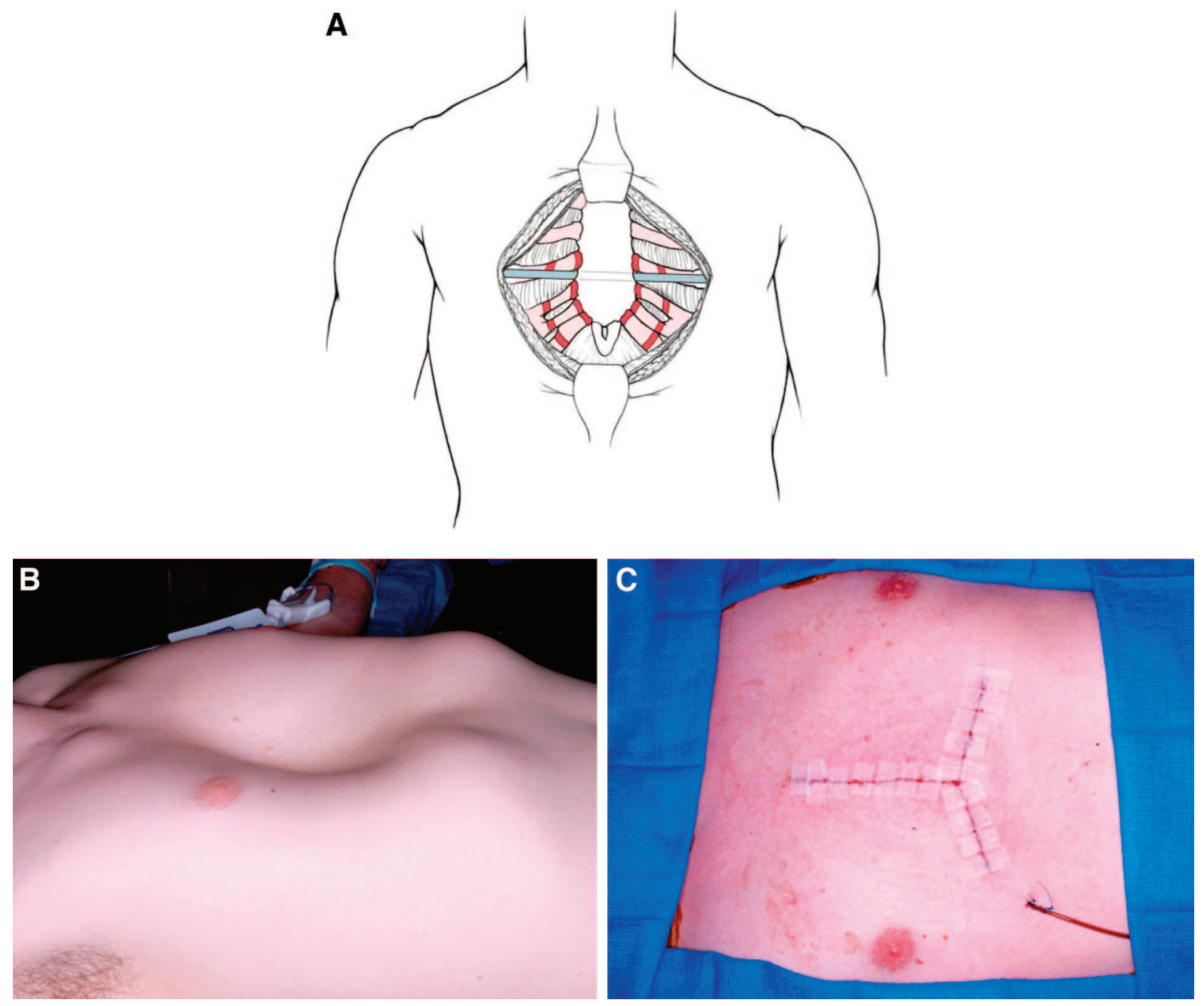

operation safer, allowing for visualization of the heart when the bar is passed retrosternal. ${ }^{29,47}$ An incidence of bar displacement rarely needing reoperation was reported at $5 \%$ to $7 \% . .^{38,42}$

Several studies have compared the 2 methods. $^{25,29,38,53,54}$ In general, the minimally invasive Nuss procedure took less time to perform but required a longer hospital stay-The open technique usually ranged from 1 to 3 days in the hospital and the minimally invasive approach ranged from 3 to 6 days-and required more postoperative analgesics than the modified Ravitch procedure. Overall, there seems to be no significant advantage for either approach. Multicenter studies about PE have demonstrated that repair by either the Nuss procedure or an open operation could be accomplished successfully with minimal complications and good pain control. . $^{25,42,43,46,53,54}$

\section{Other Repair Options}

Innovative, nonsurgical approaches are also under development and evaluation, including vacuum treatment and the use of magnetic forces. ${ }^{55,56}$ The Brazilian orthopedic surgeon, Haje, ${ }^{11,57}$ has used bracing as a nonoperative approach with success. Custom-made silicone implants have also been used with a good esthetic outcome, but the deformity and physiologic consequences of the chest wall depression are not addressed. ${ }^{58}$

\section{Conclusion}

The philosophy of PE deformity has evolved as more data and treatment experience has accrued. $\mathrm{PE}$ is no longer felt to be just a cosmetic deformity but physicians may continue to base their recommendations for surgery on limited and precon- 
Figure 7. A: Schematic drawing showing position of support bar with the Nuss procedure. B: Chest roentograph showing 2 sternal support bars after repair with the Nuss procedure. Photographs before (C) and after (D) the operation of a patient with pectus excavatum undergoing minimally invasive Nuss repair. Lateral incisions are used to place the support bar.
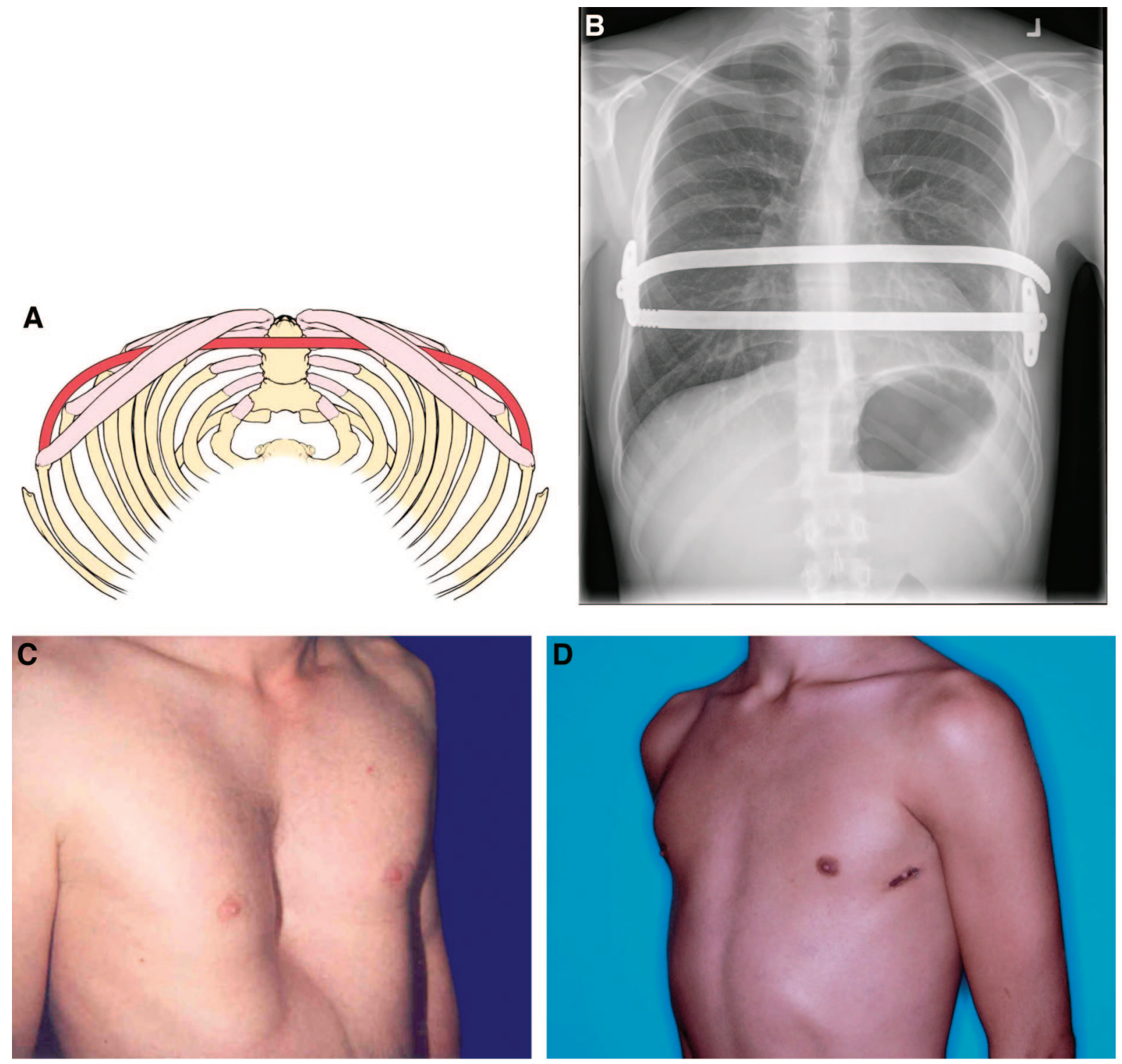

ceived knowledge from the past. As a consequence, many well-intentioned physicians advise patients that their deformity produces few symptoms and is primarily a cosmetic problem. The idea is conveyed that it will improve with age and surgical repair is complicated and unnecessary. The primary care physician has played and continues to play a critical role in the diagnosis and referral of these patients. The cardiopulmonary effects of severe deformities can be significant and may worsen as the patient ages. Surgery can be performed safely with few complications and short hospitalization. That sur-

gical treatment is performed at a high-volume center with a surgeon dedicated to pectus repair is critical to success.

\section{References}

1. Feng J, Hu T, Liu W, et al. The biomechanical, morphologic, and histochemical properties of the costal cartilages in children with pectus excavatum. J Pediatr Surg 2001;36:1770-6.

2. Fokin AA, Steuerwald N, Ahrens WA, Allen KE. Anatomical, histologic, and genetic characteristics of congenital chest wall deformities. Semin Thorac Cardiovasc Surg 2009;21:44-57. 
3. Park JM, Varma SK, Pectus excavatum in children: diagnostic significance for mitral valve prolapse. Indian J Pediatr 1990;57:219-22.

4. Sabiston JH Jr. Congenital deformities of the chest wall. In: Sabiston JH, ed. Textbook of Surgery. Philadelphia: WB Sauders Co.; 1997.

5. Fonkalsrud E, Management of pectus chest deformities in female patients. Am J Surg 2004;187:192-7.

6. Shamberger R, Congenital chest wall deformities. Curr Probl Surg 1996;33:469-552.

7. Waters P, Welch K, Micheli LJ, Shamberger R, Hall JE. Scoliosis in children with pectus excavatum and pectus carinatum. J Pediatr Orthop 1989;9:551-6.

8. Kelly R. Pectus excavatum: historical background, clinical picture, preoperative evaluation and criteria for operation. Semin Pediatr Surg 2008;17:182-93.

9. Nakaoka T, Uemura S, Yano T, Nakagawa Y, Tanimoto T, Suehiro S. Does overgrowth of costal cartilage cause pectus excavatum? A study on the lengths of ribs and costal cartilages in asymmetric patients. J Pediatr Surg 2009;44:1333-6.

10. SA Haje HH, Bowen JR. Growth disturbance of the sternum and pectus deformities: imaging studies and clinical correlation. Pediatr Radiol 1999;29:334-41.

11. SA Haje, JB, HT Harcke, et al. Disorders in the sternum growth and pectus deformities: an experimental model and clinical correlation. Acta Orthopedics Brasil 1998;6:67-75.

12. Kelly RE Jr, Lawson ML, Paidas CN, Hruban RH. Pectus excavatum in a 112-year autopsy series: anatomic findings and the effect on survival. J Pediatr Surg 2005;40:1275-8.

13. Cahill JL, Lees GM, Robertson HT. A summary of preoperative and postoperative cardiorespiratory performance in patients undergoing pectus excavatum and carinatum repair. J Pediatr Surg 1984;19: 430-3.

14. Fonkalsrud E. Current management of pectus excavatum. World J Surg 2003;27:502-8.

15. Fonkalsrud EW, Mendoza J. Open repair of pectus excavatum and carinatum deformities with minimal cartilage resection. Am J Surg 2006;191:779-84.

16. Gattiker H, Bühlmann A. Cardiopulmonary function and exercise tolerance in supine and sitting position in patients with pectus excavatum. Helv Med Acta 1966;33:122-38.

17. Haller JA Jr, Loughlin GM. Cardiorespiratory function is significantly improved following corrective surgery for severe pectus excavatum. Proposed treatment guidelines. J Cardiovasc Surg (Torino) 2000; 41:125-30.

18. Jaroszewski DE, Fonkalsrud E. Pectus deformity in the adult patient: cardiopulmonary symptoms as an indication for repair. Presented at the 27th annual International Scientific Assembly of the American College of Chest Physicians, Salt Lake City, Utah; 2006.

19. Jaroszewski DE, Fonkalsrud E. Repair of pectus chest deformities in 320 adult patients: 21 year experience. Ann Thorac Surg 2007;84:429-33.

20. Krasopoulos G, Dusmet M, Ladas G, Goldstraw P. Nuss procedure improves the quality of life in young male adults with pectus excavatum deformity. Eur J Cardiothorac Surg 2006;29:1-5.

21. Ravitch M. Pectus excavatum and heart failure. Surgery 1951;30:178-82.

22. Malek MH, Fonkalsrud EW, Cooper CB. Ventilatory and cardiovascular responses to exercise in patients with pectus excavatum. Chest 2003;124:87082.

23. Kowalewski J, Brocki M, Dryjanski T, Zolyński K, Koktysz R. Pectus excavatum: increase of right ventricular systolic, diastolic, and stroke volumes after surgical repair. J Thorac Cardiovasc Surg 1999;118: 87-93, discussion 92-3.

24. Jaroszewski D, Steidley E, Galindo A, Arabia F. Treating heart failure and dyspnea in a 78-year-old man with surgical correction of pectus excavatum. Ann Thorac Surg 2009;88:1008-10.

25. Kelly RE Jr, Shamberger RC, Mellins RB, et al. Prospective multicenter study of surgical correction of pectus excavatum: design, perioperative complications, pain and baseline pulmonary function facilitated by internet-based data collection. J Am Coll Surg 2007;205:205-16.

26. Coln D, Gunning T, Ramsay M, Swygert T, Vera R. Early experience with the Nuss minimally invasive correction of pectus excavatum in adults. World J Surg 2002;26:1217-21.

27. Rumsey N, Harcourt D. Body image and disfigurement: issues and intervention. Body Image 2004;1: 83-97.

28. Fonkalsrud EW, DeUgarte D, Choi E. Repair of pectus excavatum and carinatum deformities in 116 adults. Ann Surg 2002;236:304-12, discussion 312-4.

29. Kim do H, Hwang JJ, Lee MK, Paik HC. Analysis of the Nuss procedure for pectus excavatum in different age groups. Ann Thorac Surg 2005;80:1073-7.

30. Pilegaard HK, Licht PB. Routine use of minimally invasive surgery for pectus excavatum in adults. Ann Thorac Surg 2008;86:952-7.

31. Raggi P, Callister TQ, Lippolis NJ, Russo DJ. Is mitral valve prolapse due to cardiac entrapment in the chest cavity? A CT view. Chest 2000;117:63642.

32. Schalamon J, Pokall S, Windhaber J, Hoellwarth ME. Minimally invasive correction of pectus excavatum in adult patients. J Thorac Cardiovasc Surg 2006;132:524-9.

33. Teh S, Hanna AM, Pham TH, et al. Minimally invasive repair for pectus excavatum in adults. Ann Thorac Surg 2008;85:1914-8.

34. Tebble NJ, Thomas DW, Price P. Anxiety and selfconsciousness in patients with minor facial lacerations. J Adv Nurs 2004;47:417-26. 
35. Roberts J, Hayashi A, Anderson JO, Martin JM, Maxwell LL. Quality of life of patients who have undergone the Nuss procedure for pectus excavatum: preliminary findings. J Pediatr Surg 2003;38: 779-83.

36. Colombani P. Preoperative assessment of chest wall deformities. Semin Thorac Cardiovasc Surg 2009; 21:58-63.

37. Kelly RE Jr, Cash TF, Shamberger RC, et al. Surgical repair of pectus excavatum markedly improves body image and perceived ability for physical activity: multicenter study. Pediatrics 2008;122:1218-22.

38. Molik KA, Engum SA, Rescorla FJ, West KW, Sherer LR, Grosfeld JL. Pectus excavatum repair: experience with standard and minimal invasive techniques. J Pediatr Surg 2001;36:324-8.

39. Beiser GD, Epestein SE, Stampfer M, Goldstein RE, Noland SP, Levitsky S. Impairment of cardiac function in patient with pectus excavatum, with improvement after operative correction. N Engl J Med 1972; 287:267-72.

40. Brown AL, Cook O. Cardio-respiratory studies in pre- and post-operative funnel chest (pectus excavatum). Dis Chest 1951;20:378-91.

41. Malek MH, Berger DE, Marelich WD, Coburn JW, Beck TW, Housh TJ. Pulmonary function following surgical repair of pectus excavatum: a meta-analysis. Eur J Cardiothorac Surg 2006;30:637-43.

42. Nuss D, Kelly RE Jr, Croitoru DP, Katz ME. A 10-year review of a minimally invasive technique for the correction of pectus excavatum. J Pediatr Surg 1998;33:545-52.

43. Lam MWC, Klassen AF, Montgomery CJ, LeBlanc JG, Skarsgard ED. Quality-of-life outcomes after surgical correction of pectus excavatum: a comparison of the Ravitch and Nuss procedures. J Pediatr Surg 2008;43:819-25.

44. Wheeler R, Foote K. Pectus excavatum: studiously ignored in the United Kingdom? Arch Dis Child 2000;82:187-8.

45. Haller JA Jr, Kramer SS, Lietman SA. Use of CT scans in selection of patients for pectus excavatum surgery: a preliminary report. J Pediatr Surg 1987; 22:904-6.

46. Davis JT, Weinstein S. Repair of the pectus defor- mity: results of the Ravitch approach in the current era. Ann Thorac Surg 2004;78:421-6.

47. Nuss D, Kuhn M. Our approach: minimally invasive surgical repair of pectus excavatum. Contemp Surg 2007;63:444-51.

48. Driscoll DJ, Mottram CD. Cardiorespiratory function before and after corrective surgery in pectus excavatum. J Pediatr 1996;129:943-44.

49. Haller JA Jr, Colombani PM, Humphries CT, Azizkhan RG, Loughlin GM. Chest wall constriction after too extensive and too early operations for pectus excavatum. Ann Thorac Surg 1996;61:1618-24.

50. Aronson DC, Bosgraaf RP, van der Horst C, Ekkelkamp S. Nuss procedure: pediatric surgical solution for adults with pectus excavatum. World J Surg 2007;31:26-9, discussion, 30.

51. Fonkalsrud E. Open repair of pectus excavatum with minimal cartilage resection. Ann Surg 2004; 240:231-5.

52. Ravitch M. The operative treatment of pectus excavatum. Ann Surg 1949;129:429-44.

53. Antonoff MB, Eerickson AE, Hess DJ, Acton RD, Saltzman DA. When patients choose: comparison of Nuss, Ravitch, and Leonard procedures for primary repair of pectus excavatum. J Pediatr Surg 2009;44: 1113-8, discussion, 118-9.

54. Fonkalsrud EW, Beanes S, Hebra A, Adamson W, Tagge E. Comparison of minimally invasive and modified Ravitch pectus excavatum repair. J Pediatr Surg 2002;37:413-7.

55. Schier F. Vacuum treatment of pectus excavatum. Eur J Cardiothorac Surg 2006;30:687.

56. Harrison MR, Estefan-Ventura D, Fechter R, Moran AM Jr, Christensen D. Magnetic Mini-Mover Procedure for pectus excavatum: I. Development, design and simulations for feasibility and safety. J Pediatr Surg 2007;42:81-5, discussion, 85-6.

57. Haje S, Haje D. Orthopaedic approach to pectus deformities: 32 years of studies. Revista Brasileira de Ortopedia 2009;44:191-8.

58. Snel BJ, Spronk CA, Werker PM, van der Lei B. Pectus excavatum reconstruction with silicone implants: long-term results and a review of the Englishlanguage literature. Ann Plast Surg 2009;62:205-9. 